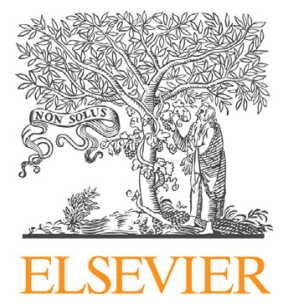

anstitute of Surgical Research, University of Szeged, Pulz U.1., Szeged, H-6724, Hungary

bepartment of General Surgery, Hetényi Géza County Hospital, Tószegi U. 21. Szolnok, H-5000, Hungary

'Department of Paediatric Urology, The Royal Manchester Children's Hospital, Oxford Road, Manchester, M13 9WL, United Kingdom

${ }^{\mathrm{d} D e p a r t m e n t}$ of Pediatric Surgery, Cairo University Specialised Pediatric Hospital (CUSPH), Faculty of Medicine (Kasr Alainy), Cairo University, Cairo, 11562, Egypt

eDepartment of Pathology, Hetényi Géza County Hospital, Tószegi U. 21., Szolnok, H5000 , Hungary

* Corresponding author. Institute of Surgical Research, University of Szeged, Pulz U.1., Szeged, H-6724, Hungary.

** Corresponding author. Department of Paediatric Urology, The Royal Manchester Children's Hospital, Oxford Road, Manchester, M13 9WL, United Kingdom.

urbandaniel03@gmail.com

(D. Urbán)

tcserni@yahoo.com, Tamas. Cserni@mft.nhs.uk (T. Cserni)

Keywords

Bladder augmentation; Mucosectomy; Flap contraction; Flap shrinkage; Enteric nervous system

Received 7 February 2019 Accepted 27 August 2019 Available online 18 September 2019

\title{
Mucosectomy disrupting the enteric nervous system causes contraction and shrinkage of gastrointestinal flaps: potential implications for augmentation cystoplasty
}

\author{
Dániel Urbán ${ }^{\mathrm{a}, \mathrm{b},{ }^{*}, \text { Mahmoud Marei Marei }}{ }^{\mathrm{c}, \mathrm{d}}$, Dániel Hajnal ${ }^{\mathrm{a}}$, \\ Gabriella Varga a, Dániel Érces ${ }^{a}$, Marietta Poles ${ }^{a}$, Dániel Imre ${ }^{e}$,

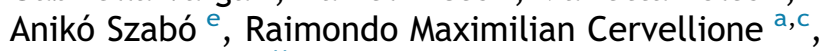 \\ Tamas Cserni ${ }^{\text {a,c,*** }}$
}

\section{Summary}

\section{Introduction}

Augmenting the bladder with a seromuscular gastrointestinal flap is a promising alternative approach aiming for a mucus-free bladder augmentation; however, the contraction (shrinkage) of the flaps remains a major concern. Enteric nervous system (ENS) abnormalities cause a failure of relaxation of the intestinal muscle layers in motility disorders such as Hirschsprung's disease and intestinal neuronal dysplasia. In mammals, the submucosal enteric nervous plexus contains nitrergic inhibitory motor neurons responsible for muscle relaxation. The authors hypothesize that mucosectomy disconnects the submucosal nervous plexus from the myenteric plexus resulting in flap shrinkage.

\section{Study design}

After ethical approval, mucosectomy was performed on vascularized flaps from the ileum, colon, and stomach in five anesthetized pigs. In Group (I), only the mucosa was scraped off with forceps, creating a sero-musculo-submucosal flap, while in Group (II), the mucosa and submucosa were peeled off as one layer, leaving a seromuscular flap. Isolated and detubularized segments served as control. The width of each flap was measured before and after the mucosectomy. The ENS was assessed by neurofilament immunohistochemistry in conventional sections and by acetylcholinesterase and NADPH-diaphorase enzyme histochemistry in whole-mount preparations.

\section{Results}

The stomach contracted to a lesser extent of its original width, $92.82 \pm 7.86 \%$ in Group (I) and $82.24 \pm 6.96 \%$ in Group (III). The ileum contracted to $81.68 \pm 4.25 \%$ in Group (I) and to $72.675 \pm 5.36 \%$ in Group (II). The shrinkage was most noticeable in the colon: $83.89 \pm 15.73 \%$ in Group (I) and to $57.13 \pm 11.51 \%$ in Group (II). Oneway equal variance test showed significant difference $(P<0,05)$ between Group (I) and (II), comparing stomach with ileum and ileum with colon. The histochemistry revealed that the submucosal nervous plexus containing nitrergic inhibitory neurons was disconnected from the myenteric plexus in Group (II) of all specimens.

\section{Conclusion}

Mucosectomy resulted in significant immediate shrinkage of the flaps. This was more expressed when also the submucosa was peeled off, thus fully disrupting the ENS. The shrinkage affected the stomach the least and the colon the greatest. This phenomenon should be taken into consideration when planning mucus-free bladder augmentation.

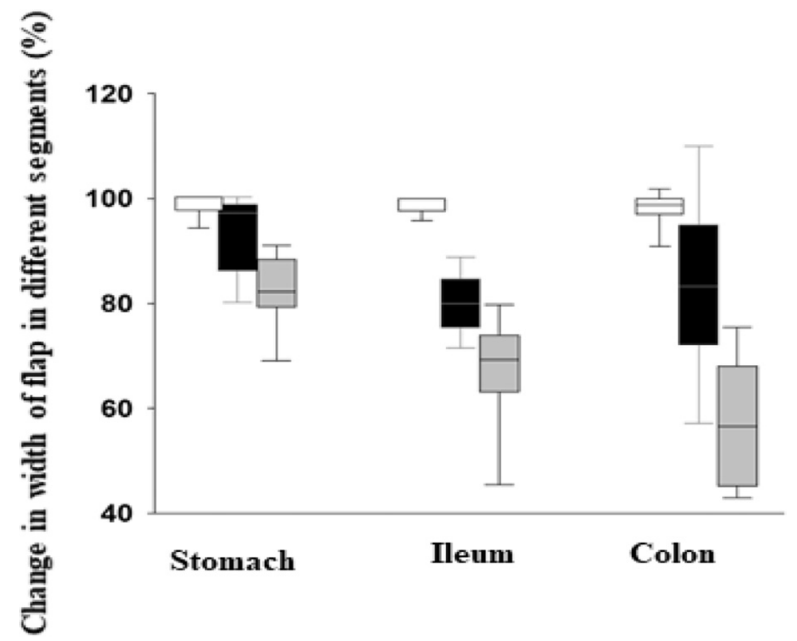

Summary Fig. 


\section{Introduction}

The presence of intestinal mucosa within the augmented bladder is associated with potential significant complications as increased infection rate because of mucus production, stone formation, absorption of electrolytes from urine, and the long-term risk of adenocarcinoma [1].

Bladder augmentation with de-mucosalized (mucosectomized) intestine or stomach has been under research since the early 1950s. Shoemaker et al. were the first to publish promising experimental results in dogs with reversed seromuscular ileal flap bladder augmentation [2]. The technique was abandoned after contraction (shrinkage) of the mucosectomized flaps occurred in four patients [3]. Thirty years later, researchers tried to revive the procedure, achieving more success in small laboratory animals such as rats and rabbits [4,5], but they were not able to reproduce good results in large animals like dogs [6,7]. Despite the lack of a definite explanation, multiple researchers acknowledged that there are variable results in experimental animals of different sizes.

It had been suggested that the shrinkage of the flaps is possibly multifactorial because of (a) chemically induced fibrosis caused by the exposure of the raw surface to urine, (b) chronic infection, (c) prolonged postoperative decompression of the bladder, and/or (d) ischemia occurring during the mucosectomy [5]. Researchers are now attempting to eliminate the chemical irritation caused by urine on the mucosectomized raw surface of the flaps using urothelium, and despite the use of postoperative splints, the shrinkage of flaps remains a significant problem [8-10].

To the authors knowledge, the effect of mucosectomy on the enteric nervous system (ENS) of the intestinal flaps has not been studied yet. However, it is well known that an intact ENS is essential to maintain the intestinal structure and function. Abnormal ENS is responsible for failure of relaxation of the intestinal muscle layers in motility disorders as Hirschsprung's disease (HD) and intestinal neuronal dysplasia [11]. There is a significant structural difference in the ENS of small rodents and large mammals. While in small rodents motor neurons are located only in the myenteric plexus, in mammals the submucosal plexus contains nitrergic inhibitory motor neurons, which are responsible for muscle relaxation [12].

The authors hypothesize that mucosectomy because of disrupting the nitrergic neurons in the submucosa of large mammals has a similar effect to dysganglionosis. This may explain flap contraction and shrinkage, as well as the variable experimental results with sero-muscular bladder augmentation observed in different species.

In previous reports and available literature about this topic, the term contraction was used although the phenomenon is not an active cyclic relaxation/contraction in response to an intermittent stimulus but rather a maintained flap shrinkage because of increased muscle tone. The authors therefore used the term flap shrinkage throughout this report.

\section{Material and methods}

The experiments were performed according to EU Directive 2010/63/EU on the protection of animals used for experimental and other scientific purposes and carried out in strict adherence to the National Institutes of Health (NIH) guidelines for the use of experimental animals. The study was approved by the National Scientific Ethical Committee on Animal Experimentation, with the license number: V./1637/ 2013. The study was performed on anesthetized female Vietnamese mini pigs ( $n=5$; weight $=30-45 \mathrm{~kg})$. The animals were kept under conventional circumstances, in standard cages, were fed with commercially available mixed food, were fasted for $24 \mathrm{~h}$ before surgery, and always had free access to water. Anesthesia was induced by an intramuscular injection of a mixture of ketamine $(20 \mathrm{mg} / \mathrm{kg})$ and xylazine $(2 \mathrm{mg} / \mathrm{kg})$ and maintained with a continuous infusion of propofol (2\%) at a rate of $50 \mathrm{~mL} / \mathrm{kg} / \mathrm{min}$ IV via a cannulated ear vein. An endotracheal tube was inserted, and then, the animals were ventilated mechanically with a volume-controlled ventilator. The tidal volume was set at $8-9 \mathrm{~mL} / \mathrm{kg}$, and the respiratory rate was adjusted to maintain the end-tidal carbon dioxide pressure $\left(\mathrm{EtCO}_{2}\right)$ between 35 and $45 \mathrm{mmHg}$. Norocarp S (carprofen) at $4 \mathrm{mg} / \mathrm{kg}$ and normal saline infusion were also administered via an ear vein cannula. Heart rate, $\mathrm{O}_{2}$ saturation (pulse oximetry), $\mathrm{EtCO}_{2}$ (capnometry), and body temperature were continuously monitored peri-operatively.

In each animal, three 5 -cm-long ileum and colonic segments were isolated and de-tubularized along the mesenteric line, one of the three segments was allocated to the control group and one to each of the experimental groups, Group (I) and (II). Similarly, three $5 \mathrm{~cm} \times 5 \mathrm{~cm}$ segments were created in each animal from the stomach at the greater curvature preserving the right gastroepiploic artery. The segments were kept warm with $0.9 \%$ saline solution. The de-tubularized bowel and stomach flaps were placed on wet gauze, and the width was measured with linear ruler under no tension and without delay.

The mucosectomy was performed in two groups (a segment from each animal was allocated to each group). In Group I (sero-musculo-submucosal flap group), only the mucosa was scraped off with the back of the forceps from all segments, at the level of the lamina propria mucosae. In Group II (sero-muscular flap group), the submucosa was separated from the sero-muscular layer at the edge of the flap with fine forceps, using $2.5 \mathrm{X}$ magnification, and peeled away from the sero-muscular layer in one piece. The mucosectomized flaps of both groups were then placed on wet gauze and measured again with a linear ruler with no tension and with no significant delay. The whole duration of this part of the experiment was 2 hours for each pig. In Group (I), histology samples were taken from the seromusculo-submucosal flaps. In Group (II), the specimens were taken from the sero-muscular layer, and the mucosasubmucosa layer which was peeled away. After fixation in $4 \%$ formalin, the specimens were embedded in paraffin, and staining was done with conventional hematoxylin and eosin and neurofilament immunohistochemistry with Monoclonal Mouse Anti-Human Neurofilament Protein Clone 2F11, Code-Nr. M 0762 (DakoCytomation). 
For standard NADPH-diaphorase and acetylcholine esterase (AchE) enzyme histochemistry, $1 \mathrm{~cm} \times 1 \mathrm{~cm}$ specimens were excised from the mucosa-submucosa layer, which was pealed away from the sero-muscular layer. The whole mount preparations were incubated in $1 \mathrm{mg} / \mathrm{mL} \beta-\mathrm{NADPH}$ (Sigma), $0.25 \mathrm{mg} / \mathrm{mL}$ nitro blue tetrazolium, and $0.3 \%$ Triton- $X$ in $0.05 \mathrm{~mol} / \mathrm{L}$ Tris-HCL buffer $(\mathrm{pH}$ 7.6) at $37^{\circ} \mathrm{C}$ for 2 hours and then left in staining solution at room temperature. After the desired staining intensity was achieved, the specimens were washed in phosphate buffered saline for 15 minutes and processed by the standard AchE histochemistry. The specimens were placed in $10 \mathrm{~mL}$ of an incubating solution $(65 \mathrm{mM}$ sodium acetate buffer, $\mathrm{pH}$ 6.0, $1.7 \mathrm{mM}$ acetylthiocholine iodide, $5 \mathrm{mM}$ sodium citrate, $3 \mathrm{mM}$ cupric sulfate, and $0.5 \mathrm{mM}$ potassium ferricyanide) for $100 \mathrm{~min}$ at $37^{\circ} \mathrm{C}$. Tissues were then rinsed twice in $0.1 \mathrm{M}$ Tris buffer ( $\mathrm{pH} 7.6)$ and mounted on polysine slides (BDH) using Glycergel mounting medium (DakoCytomation).

The slides were examined with an Olympus BX 63 light microscope, and they were scanned with a 3DHistech Panoramic MIDI II device. The animals were sacrificed after the procedure. The specimens were compared and contrasted to each other.

Data analysis was performed with a statistical software (Sigmaplot 13.0.0/2017 for Windows by Systat Software Inc.). To test for differences between the different groups, the authors used Shapiro-Wilk normality test and analysis of variance (one and two-way). $P$-values $<0.05$ were considered significant.

\section{Results}

There was no significant difference in the original size of the segments from the stomach, ileum and colon, measured across the different animals $(n=5)$.

The stomach contracted to a lesser extent of its original width, $92.82 \pm 7.86 \%$ in Group (I) and $82.24 \pm 6.96 \%$ in Group (II). The ileum contracted to $81.68 \pm 4.25 \%$ in Group (I) and to $72.675 \pm 5.36 \%$ in Group (II). The flap shrinkage was most significant in the colon, down to $83.89 \pm 15.73 \%$ in Group (I) and to $57.13 \pm 11.51 \%$ in Group (II). One-way equal variance test showed a significant difference $(P<0.05)$ for each segment between Group (I) and (II), comparing the stomach to the ileum and the ileum to the colon. Results are summarized in Fig. 1.

Hematoxylin and eosin staining: The same features were observed consistently in all flaps. In Group (I), small mucosal remnants were observed on the top of the muscularis mucosae. In Group (II), the submucosal layer was completely missing.

Neurofilament immunohistochemistry: In Group (I), all plexuses, the superficial and deep submucosal and the myenteric plexuses, were intact in all flaps (Fig. 2A, Figs. $3 A$ and $3 C$ ). In Group (II), irrespective of whether it was ileum, colon, or stomach, only the myenteric plexus could be observed intact. In any individual slide, only 1-2 submucosal ganglia were occasionally found loosely attached to the sero-muscular flap (Fig. 2B), and the vast majority of the deep and superficial ganglia were missing. These ganglia could be observed in the removed submucosamucosal layer (Fig. 2C, Figs. 3B and 3D).

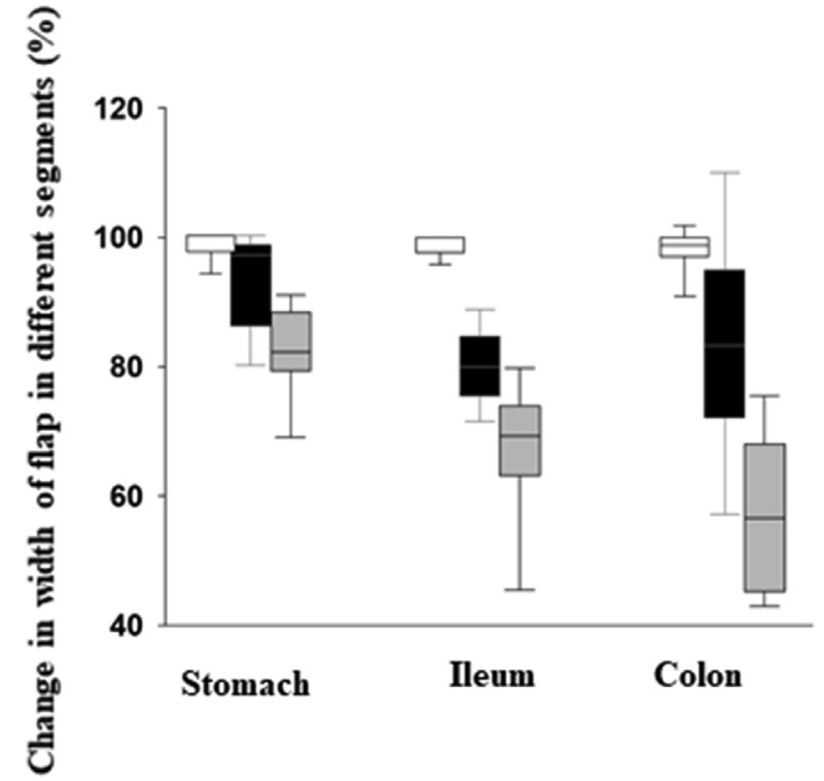

Fig. 1 The width of the flaps in the control [white], the mucosectomy (Group I) [black] and the sero-muscular groups (Group II) [grey]. Two-way Equal Variance Test showed significant difference $(P<0,05)$ in each segment between Group I and II, whether between stomach and ileum or between ileum and colon.

Whole-mount preparation and AchE and NADPHd enzymhistochemistry: The full plexus of submucosal ganglia was found on the surface of the submucosal layer that was previously facing the muscle layers. Cholinergic neurons stained brown while nitrergic neurons stained blue in the submucosal ganglia (Fig. 2D).

\section{Discussion}

Augmentation with de-mucosalized intestinal segment is still not fully reliable and did not gain widespread popularity. The main concern is the flap shrinkage, which is still poorly understood. This study provides evidence that mucosectomy clearly has a significant immediate effect on the dimensions of the gastrointestinal segments, irrespective of whether it is a stomach, ileum, or colon. The study results also offer an explanation to why shrinkage of the mucosectomized flaps is unavoidable in large animals, while in previous studies on smaller mammals in which motor neurons are only located in the myeneteric plexus, this phenomenon has not been observed.

During ENS development, the neural crest cells first form the myenteric plexus immediately outside the circular muscle layer. The mesenchymally derived longitudinal muscle layer then forms outside this, sandwiching the myenteric plexus after it has been formed, and the submucous plexus is then formed by the neuroblasts, which migrate from the myenteric plexus across the circular muscle layer and into the submucosa and from that point neurons extend into the mucosa [13]. The neurons that project to the mucosa include intrinsic sensory [14] and secretomotor neurons $[15,16]$. The submucosal plexus acts 

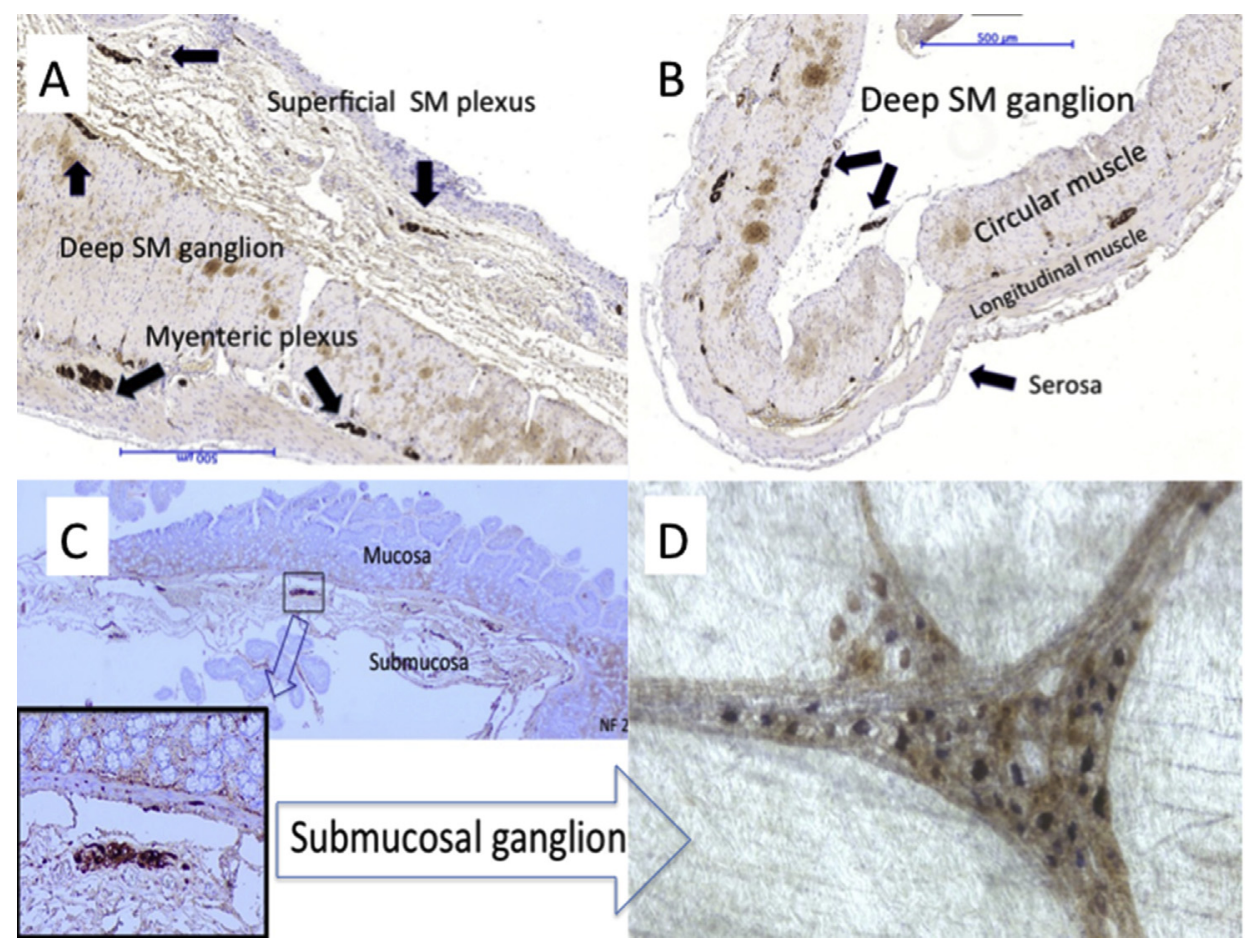

Fig. 2 Ileal flap. A: In Group I, all plexuses, the superficial and deep submucosal and the myenteric plexuses were intact (Conventional section, Neurofilament immunostaining); B: In Group II, only 1-2 submucosal ganglia were attached loosely to the sero-muscular flap, vast majority of the deep and superficial ganglia are missing. (Conventional section, Neurofilament immunostaining); C: Submucosal ganglia can be observed in the removed submucosa-mucosal layer. (Conventional section, Neurofilament immunostaining); D: The full plexus of submucosal ganglia was found on the surface of the submucosal layer used to face to the muscle layers. Cholinergic neurons stained brown while nitrergic neurons stained blue. (Whole-mount preparate, NADPH-d, and AchE enzyme histochemistry). AchE, acetylcholine esterase; NADPH-d, NADPH-diaphorase.

A

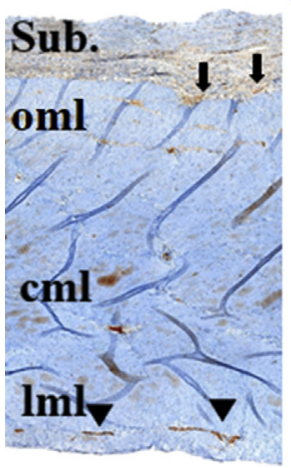

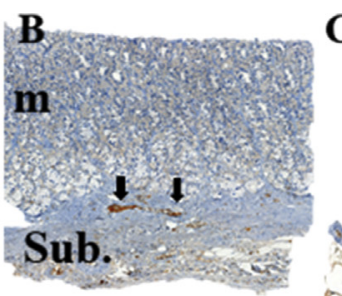

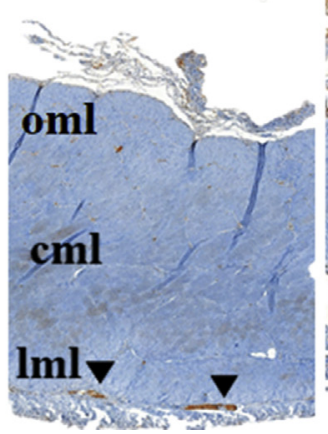

C

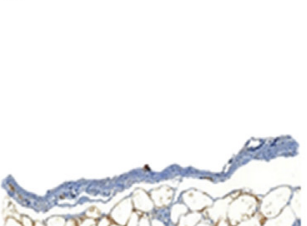

Sub.
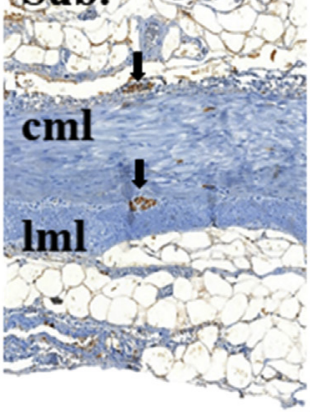

D

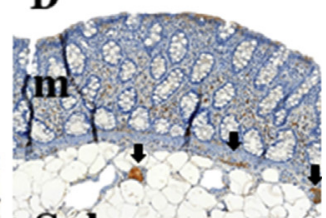

Sub.
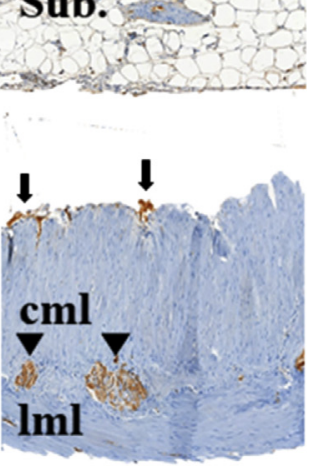

Fig. 3 A: Stomach flap after scraping off the mucosa (Group I); B: Stomach flap after total removal of the mucosa-submucosa layer (Group II), the removed mucosa is on the top and the sero-muscular layer is on the bottom; C: Colon flap after scraping off the mucosa (Group I); D: Colon flap after total removal of the mucosa-submucosa layer (Group II), the removed mucosa is on the top and the sero-muscular layer is on the bottom. Arrowheads, submucous plexus; arrows, myenteric plexus; m, mucosa; sub, submucosa; cml, circular muscle layer; Iml, longitudinal muscle layer. 
as a bridge of signals between the musculosa (muscularis layer or muscle coat) and the mucosa of the gut [17]. Submucosal neurons connect to each other, to the mucosa, and to the myenteric plexus, so that disruption of this fine network at any level detrimentally affects the physiology of motility and vascularity [18-20].

This understanding is in keeping with the observations in this study that flap shrinkage occurred in both of the studied groups (I) and (II), albeit to a lesser degree when only the mucosa was scrapped off in group (I), while it occurred more significantly when the submucosal plexus was fully disrupted in group (II). The flap shrinkage that the authors recorded was an instant phenomenon after mucosectomy. This can be explained with the disrupted nerve fibers connecting submucous and myenteric ganglia. In that situation, the inhibitory motoneurons located in the submucosa cannot suppress the myenteric cholinergic motoneurons, which being un-inhibited would induce an increased muscle tone and contraction of the muscle fibers.

As sensory nerve fibers are present in the mucosa, the authors can speculate that disrupting the nerve fibers between the mucosa and the ENS [as in group (I) specimens] may have an effect on the fine reflex circuits of the intestine responsible for motor integrity, including both muscle tone and contractility. Disruption of the submucosa [as in group (II) specimens], would obviously have a more accentuated effect [18-20].

Increased baseline muscle tone is observed in HD, where the myenteric plexus is under-developed and inhibitory motoneurons are missing. The muscle layer is therefore unable to relax, which is the diagnostic feature of HD in anorectal manometry. Increased AchE-positivity is a diagnostic histological feature of $\mathrm{HD}$, which comes from the hypertrophied AchE-positive uninhibited excitatory nerve endings [11]. The fine balance of the excitatory and inhibitory neural circuits responsible for normal muscle tone and motility does not exists if the ENS is not fully developed and intact. Similarly, decreased peptidergic and nitrergic innervation (inhibitory motoneurons) has been hypothesized as an etiology for intrinsic pelvi-ureteric junction obstruction because of failure to relax to stimuli (urine bolus), and it is at least suspected as an etiology of hypertrophic pyloric stenosis [21-23].

Zhang et al. (2011) found that botulinum toxin infiltration of the mucosectomized gastric flaps is able to prevent flap contraction (shrinkage) [9]. This clearly supports this study's hypothesis; however, a clear explanation as to how and why did this happen was not reached then. It is plausible that non-specific paralysis of the imbalanced nerve circuits of the stomach after mucosectomy resulted in muscle relaxation, i.e. prevented the shrinkage of the flaps. Other drugs, such as local anesthetics, NO gas, nitric oxide synthase, and botulinum toxin, can prevent contractions; however, in the current study, the authors did not pursue testing this because the accurate administration and dosage of these drugs would have complicated our analysis, as confounding factors and most likely would have had a temporary effect of variable and unknown duration.

There was a significant difference between the three organs in the extent of flap shrinkage. It affected the stomach lesser and the colon greater. The authors can only speculate that this is affected by the anatomy and spatial pattern of the muscle layers of these organs. The more developed the individual layers (circular, oblique, and longitudinal), the more likely they can oppose sliding and hold-on to one-another thus oppose contraction and shrinkage. The flaps were de-tubularized along the longitudinal axis, thus the width of the flaps the authors measured was coming from the length of the de-tubularized circular muscle fibers. Consequently, the circular muscle fibers had the most significant effect. The presence of a complete sheet of longitudinal and oblique muscle layers in the stomach would keep the circular fibers more fixed than in the ileum, which lacks an oblique layer, and even more than in the colon, which lacks an oblique layer and has a poorly developed longitudinal layer, arranged in three equally spaced lines (teniae coli). Additionally, there may be subtle differences between the ENS of the stomach, ileum, and colon, which may contribute to these differences.

One can argue that surgical manipulation alone may have induced the contraction of the bowel flaps. However, the control group, where bowel segments were isolated and de-tubularized was exposed to a degree of surgical manipulation as well, although admittedly, scraping off the mucosa or pealing the submucosa is a stronger stimulus than de-tubularization. The only difference between the control group (on one hand) and Groups I and II (put together, on the other hand) is the mucosectomy; therefore, the phenomenon of contraction (shrinkage) that was reliably observed must be the result of the mucosectomy. Furthermore, the flap shrinkage was significantly more expressed in Group (II) vs Group (I) because of the proven more disruption of the ENS in Group (II).

Obviously, the surgeon can compensate for the shrinkage of the flaps by harvesting longer bowel loops for augmentation, but this has to be done before performing the mucosectomy. However, it is highly likely the bowel segment will still behave like one with $\mathrm{HD}$, i.e. will not be able to relax; therefore, the authors can expect less compliance once augmentation is done with mucosectomy. The main message is that this should be considered when planning an augmentation using a de-mucosalized flap.

It is noteworthy that, augmentation with sero-musculosubmucosal intestinal flaps does not result in a totally mucus-free bladder, as the mucosa will regrow [24-26]. Despite that the authors were very meticulous and used surgical loops with $2.5 \mathrm{X}$ magnification during the mucosectomy, they saw mucosal island on the flaps after H\&E staining.

In a previous study, the authors found that significant disruption of the intrinsic blood supply and microcirculation of the flaps may result in long-term ischemia and fibrosis [27]. By highlighting this, together with the current observation of damaged ENS and acute shrinkage, the authors aim to contribute to the discussion pertinent to microvascular and neuronal aspects of the valued and innovative experimental efforts to remove or replace the mucosal coverage of the gastrointestinal flaps used for augmentation.

The limitation of this study is that the authors did not monitor the shrinkage in the long term; however, they did not observe any improvement during the 2-hours' duration of this step or part of the experiment, in each pig. In a 
previous animal study, where microcirculation of the mucosectomized ileal flaps was assessed before and after mucosectomy and the flaps were used for augmentation in a reverse fashion, the authors were able to demonstrate the long-term shrinkage of both types of these flaps [27].

\section{Conclusion}

Mucus-free bladder augmentation with intestinal segments remains a challenge; the present and previous study clearly demonstrated that surgical removal of the mucosa and/or submucosa has a significant impact on the innervation and microcirculation of the intestinal flap, which may explain flap shrinkage even before flap exposure to urine. The authors believe that efforts for mucus-free bladder augmentation with mucosa-replacement gastrointestinal segments should take this phenomenon into consideration.

\section{Author statements}

\section{Ethical approval}

The study was approved by the National Scientific Ethical Committee on Animal Experimentation, with the license number: V./1637/2013.

\section{Funding}

This study was supported by research grants from the Economic Develpoment and Innovation Operational Programme (Gazdaságfejlesztési és Innovációs Operatív Program: GINOP-2.3.2-15-2016-00034) and the Human Resource Development Operative Programme (Emberi Erőforrás Fejlesztési Operatív Program: EFOP-3.6.2-162017-00006).

\section{Competing interest}

The authors declare that they have no competing interests.

\section{References}

[1] Kropp BP, Cheng EY. Bladder augmentation: current and future techniques. In: Docimo SG, Canning DA, Khoury AE, editors. Clinical Pediatric Urology. London: Informa Healthcare; 2007. p. 871-910.

[2] Shoemaker WC. Reversed seromuscular grafts in urinary tract reconstruction. J Urol 1955 Oct;74(4):453-75. https: //doi.org/10.1016/s0022-5347(17)67305-1.

[3] Shoemaker WC, Bower R, Long Jr D. A new technique for bladder reconstruction. Surg Gynecol Obstet 1957 Nov;105(5): 645-50. PMID: 13486430.

[4] Oesch I. Neourothelium in bladder augmentation. An experimental study in rats. Eur Urol 1988;14(4):328-9. https: //doi.org/10.1159/000472971.

[5] Salle JL, Jednek R. Fibrosis of the seromuscular segment. In: Dewan P, Mitchell ME, editors. Bladder Augmentation. London: Arnold; 2000. p. 28-9. \& p. 80-81.

[6] Salle JL, Homayoon K, Agarwal SK, Sanjiv K, Bagli DJ, Mclorie GA, et al. Determining factor in the contraction of de- epithelialised gastric flap for bladder augmentation. J Urol 1997; 157:769A.

[7] Cheng E, Rento R, Grayhack JT, Oyasu R, McVary KT. Reversed seromuscular flaps in the urinary tract in dogs. J Urol 1994 Dec;152(6 Pt 2):2252-7. https://doi.org/10.1016/s00225347(17)31652-x.

[8] Turner A, Subramanian R, Thomas DF, Hinley J, Abbas SK, Stahlschmidt J, et al. Transplantation of autologous differentiated urothelium in an experimental model of composite cystoplasty. Eur Urol 2011 Mar;59(3):447-54. https: //doi.org/10.1016/j.eururo.2010.12.004.

[9] Zhang Y, Liu G, Kropp BP. Re-epithelialization of demucosalized stomach patch with tissue-engineered urothelial mucosa combined with Botox A in bladder augmentation. BJU Int 2012 Jul;110(2 Pt 2):E106-12. https://doi.org/10.1111/j.1464410X.2011.10845.x.

[10] Hidas G, Lee HJ, Bahoric A, Kelly MS, Watts B, Liu Z, et al. Aerosol transfer of bladder urothelial and smooth muscle cells onto demucosalized colonic segments for bladder augmentation: in vivo, long term, and functional pilot study. J Pediatr Urol 2015 Oct;11(5):260.e1-6. https://doi.org/10.1016/j. jpurol.2015.02.020.

[11] Teitelbaum DH, Coran AG. Hirschsprung's disease and related neuromuscular disorders of the intestine. In: Grosfeld JL, O'Neill JA, Coran AG, Fonkalsrud EW, editors. Pediatric Surgery. Chapter 99, 6th ed. U.S.A.: Mosby; 2006. p. 1514-59. p. 1527.

[12] Furness JB. The enteric nervous system and neurogastroenterology. Nat Rev Gastroenterol Hepatol 2012 Mar 6; 9(5):286-94. https://doi.org/10.1038/nrgastro.2012.32.

[13] Martucciello G, Pini Prato A, Puri P, Holschneider AM, MeierRuge W, Jasonni V, et al. Controversies concerning diagnostic guidelines for anomalies of the enteric nervous system: a report from the fourth International Symposium on Hirschsprung's disease and related neurocristopathies. J Pediatr Surg 2005 Oct;40(10):1527-31.

[14] Bornstein JD, Furness JB. Correlated electrophysiological and histochemical studies of submucous neurons and their contribution to understanding enteric neural circuits. J Auton Nerv Syst 1988;25(1):1-13. https://doi.org/10.1016/01651838(88)90002-1.

[15] Frieling T, Cooke HJ, Wood JD. Electrophysiological properties of neurons in submucosal ganglia of Guinea pig distal colon. Am J Physiol 1991 Jun;260(6 Pt 1):G835-41. https: //doi.org/10.1152/ajpgi.1991.260.6.G835.

[16] Rolle U, Nemeth L, Puri P. Nitrergic innervation of the normal gut and in motility disorders of childhood. J Pediatr Surg 2002 Apr;37(4):551-67. https://doi.org/10.1053/jpsu.2002.31610.

[17] Puri P, Rolle U. Development of the enteric nervous system. In: Holschneider AM, Puri P, editors. Hirschsprung's Disease and Allied Disorders. Chapter 2, 3rd ed. Berlin Heidelberg: Springer-Verlag; 2008. p. 13-20.

[18] Román V, Bagyánszki M, Krecsmarik M, Horváth A, Resch BA, Fekete $E$. Spatial pattern analysis of nitrergic neurons in the developing myenteric plexus of the human fetal intestine. Cytometry 2004 Feb;57(2):108-12. https://doi.org/10.1002/ cyto.a.10112.

[19] Brandt CT, Tam PK, Gould SJ. Nitrergic innervation of the human gut during early fetal development. J Pediatr Surg 1996 May;31(5):661-4. https://doi.org/10.1016/s0022-3468(96) 90669-7.

[20] Foxx-Orenstein AE, Kuemmerle JF, Grider JR. Distinct 5-HT receptors mediate the peristaltic reflex induced by mucosal stimuli in human and Guinea pig intestine. Gastroenterology 1996 Nov;111(5):1281-90. https://doi.org/10.1053/gast. 1996.v111.pm8898642.

[21] Knerr I, Dittrich K, Miller J, Kummer W, Rösch W, Weidner W, et al. Alteration of neuronal and endothelial nitric oxide 
synthase and neuropeptide $Y$ in congenital ureteropelvic junction obstruction. Urol Res 2001 Apr;29(2):134-40. https: //doi.org/10.1007/s002400000165.

[22] Wang Y, Puri P, Hassan J, Miyakita H, Reen DJ. Abnormal innervation and altered nerve growth factor messenger ribonucleic acid expression in ureteropelvic junction obstruction. J Urol 1995 Aug;154(2 Pt 2):679-83. https://doi.org/10. 1097/00005392-199508000-00091.

[23] Vanderwinden JM, Mailleux P, Schiffmann SN, Vanderhaeghen JJ, De Laet MH. Nitric oxide synthase activity in infantile hypertrophic pyloric stenosis. N Engl J Med 1992 Aug 20;327(8). https://doi.org/10.1056/NEJM199208203270802. 511-5. Erratum in N Engl J Med 1992 Oct 22;327(17):1252.

[24] Dewan PA, Close CE, Byard RW, Ashwood PJ, Mitchell ME. Enteric mucosal regrowth after bladder augmentation using demucosalized gut segments. J Urol 1997 Sep;158(3 Pt 2):
1141-6. https://doi.org/10.1097/00005392-19970900000114.

[25] Jednak R, Schimke CM, Barroso UJR, Barthold JS, González R. Further experience with seromuscular colocystoplasty lined with urothelium. J Urol 2000 Dec;164(6):2045-9. PMID: 11061922.

[26] Fraser M, Thomas DF, Pitt E, Harnden P, Trejdosiewicz LK, Southgate J. A surgical model of composite cystoplasty with cultured urothelial cells: a controlled study of gross outcome and urothelial phenotype. BJU Int 2004 Mar;93(4):609-16. https://doi.org/10.1111/j.1464-410x.2003.04675.x.

[27] Cervellione RM, Hajnal D, Varga G, Rakoczy G, Kaszaki J, Keene $D$, et al. Mucosectomy impairs ileal microcirculation and results in flap contraction after experimental ileocystoplasty. J Pediatr Urol 2017 Feb;13(1):81.e1-5. https: //doi.org/10.1016/j.jpurol.2016.11.007. 